\title{
Strategies of Increased Protein Intake in ELBW Infants Fed by Human Milk Lead to Long Term Benefits
}

\author{
Elisa Mariani i* ${ }^{1 *}$ Augusto Biasini ${ }^{2}$, Lucia Marvulli ${ }^{1}$, Silvia Martini ${ }^{3}$, Arianna Aceti ${ }^{3}$, \\ Giacomo Faldella ${ }^{3}$, Luigi Corvaglia ${ }^{3}$, Alessandra Sansavini ${ }^{4}$, Silvia Savini ${ }^{3}$, \\ Francesca Agostini ${ }^{4}$, Marcello Stella ${ }^{1}$ and Erica Neri ${ }^{4}$
}

${ }^{1}$ Pediatric and Neonatal Intensive Care Unit, M. Bufalini Hospital, Cesena, Italy, ${ }^{2}$ Donor Human Milk Bank Italian Association (AIBLUD), Milan, Italy, ${ }^{3}$ Neonatology and Neonatal Intensive Care Unit-S. Orsola-Malpighi Hospital, Bologna, Italy,

${ }^{4}$ Department of Psychology, University of Bologna, Bologna, Italy

OPEN ACCESS

Edited by:

Guido Eugenio Moro,

Donor Human Milk Bank Italian

Association (AIBLUD), Italy

Reviewed by:

Paolo Ghirri,

Università degli Studi di Pisa, Italy

Monika Sharma,

Christian Medical College \& Hospital,

India

*Correspondence:

Elisa Mariani

elisa.mariani@auslromagna.it

Specialty section

This article was submitted to

Children and Health,

a section of the journal

Frontiers in Public Health

Received: 02 July 2018 Accepted: 31 August 2018

Published: 27 September 2018

Citation

Mariani E, Biasini A, Marvulli L,

Martini S, Aceti A, Faldella G,

Corvaglia L, Sansavini A, Savini S, Agostini F, Stella M and Neri E (2018) Strategies of Increased Protein Intake in ELBW Infants Fed by Human Milk Lead to Long Term Benefits. Front. Public Health 6:272.

doi: 10.3389/fpubh.2018.00272
Objective: The aim of this observational study was to evaluate the effects of two different protein intake regimes on feeding tolerance, in-hospital growth, anthropometric data and psychomotor outcome up to 24 months corrected age (CA) in extremely low birth-weight (ELBW; birth weight $<1000 \mathrm{~g}$ ) infants.

Methods: During the period 2008-2013, 52 ELBW infants admitted at birth to two Neonatal Intensive Care Units of Emilia Romagna (Italy) were fed according to different protocols of protein fortification of human milk: an estimated protein intakes at maximum fortification levels of $3.5 \mathrm{gr} / \mathrm{kg} /$ day in the Standard Nutrition Population-SNP group $(n=26)$ and $4.8 \mathrm{~g} / \mathrm{kg} /$ day in the Aggressive Nutrition Population-ANP group ( $n=26)$. During hospitalization, infants' growth, biochemical indices of nutritional status, enteral intake, feeding tolerance, clinical history and morbidity were evaluated. After discharge, anthropometric data and psychomotor outcome, evaluated by Revised Griffiths Mental Development Scales (GMDS-R) 0-2 years, were assessed up to 24 months CA.

Results: During hospitalization, the ANP group showed significantly higher weight (18.87 vs. $15.20 \mathrm{~g} / \mathrm{kg} /$ day) and head circumference (0.70 vs. $0.52 \mathrm{~cm} /$ week) growth rates compared to SNP, less days of parenteral nutrition (7.36 \pm 2.7 vs. $37.75 \pm$ 29.6) and of hospitalization (60.0 \pm 13.3 vs. $78.08 \pm 21.32$ ). After discharge, ANP infants had a greater head circumference compared to SNP (45.64 $\pm 0.29 ; 46.80 \pm$ 0.31). Furthermore, the General Quotient of GMDS-R mean scores in the SNP group significantly decreased from 12 to 24 months CA, while no difference was seen in the ANP group.

Conclusions: Increased protein intake may provide short and long term benefits in terms of growth and neurodevelopment in human milk-fed ELBW infants.

Keywords: nutrition ELBW, protein intake, long term neurologic advantages, full feeding achievement, speed of growth 


\section{INTRODUCTION}

The main goals of preterm infants' nutrition are the achievement of postnatal growth rates similar to those of normal fetuses of the same gestational age, a mimic fetal body composition and neurodevelopmental outcomes comparable to term-born infants (1).

In-hospital weight, length, and head circumference (HC) growth rates are positively correlated with neurodevelopment and, possibly, with an improved brain growth and neurological maturation in the preterm population $(2,3)$. Conversely, extrauterine growth restriction (EUGR), defined as weight, length, or $\mathrm{HC} \leq 10$ th percentile of intra-uterine growth expectation for correspondent postmenstrual age at hospital discharge (4), is a negative prognostic factor for long-term neurodevelopment (2). Adequate nutrition during hospitalization is fundamental in order to prevent EUGR and to optimize long-term growth and neurodevelopment in the preterm population. However, due to their gastro-intestinal immaturity, very preterm infants often experience poor feeding tolerance during their stay in Neonatal Intensive Care Unit (NICU), and this contributes to hinder the achievement of optimal nutritional intakes over the first weeks of life (5). As a consequence, significant energy and nutrients deficits are frequently established during NICU stay, and inadequate protein and energy intakes may account for up to $45 \%$ of postnatal weight restriction in very-low-birth-weight preterm infants at hospital discharge $(6,7)$.

The beneficial effects of human milk feeding have been currently acknowledged to overcome the delayed weight gain associated to the lower protein and energy contents of human milk compared to formula $(8,9)$. However, it has been previously shown that actual protein intakes after standard protein fortification of human milk are substantially lower than those recommended over the first weeks of life $(10,11)$. Furthermore, data on the possible influence of protein intakes on neonatal growth and neurodevelopment in extremely low birth weight (ELBW) infants are still limited (12).

This study aimed to evaluate the effect of two nutritional approaches, providing different protein regimens, on in-hospital and post-discharge growth and psychomotor outcomes in ELBW preterm infants followed up to 24 months of corrected age (CA).

\section{MATERIALS AND METHODS}

During the period 2008-2013, all preterm infants admitted to two level III NICUs of Emilia Romagna region (Italy), Sant'Orsola Malpighi Hospital NICU (Bologna) and Bufalini Hospital NICU (Cesena), were included in the present study if the following inclusion criteria were fulfilled: birth-weight (BW) $<1000$ g, gestational age $(\mathrm{GA})<32$ weeks, exclusive human milk feeding (own mother's milk [OMM] or donor milk [DM] from the local human milk bank) during NICU stay, no presence of sepsis. Conversely, infants developing intraventricular hemorrhage grade 3 or 4 (13), periventricular leukomalacia (14), retinopathy of prematurity $\geq$ grade 3 plus disease (15), or necrotizing enterocolitis (NEC) Bell's stage $\geq 2$ (16) during hospitalization were ruled out from the study, in view of the known negative effects of these conditions on growth and development. Globally, 52 ELBW infants were considered eligible for the study.

This study was conducted in conformity with the principles and regulations of the Helsinki Declaration. A written, informed consent to participate was obtained from the parents/guardians of each infant. The protocol was approved by the local Ethics Committees in both the study centers.

\section{Strategies}

The two NICUs had similar protocols for resuscitation, stabilization, ventilation and pharmacological management of ELBW preterm infants, whereas their nutritional approaches were significantly different.

The nutritional protocol of Sant'Orsola Malpighi Hospital's NICU, named Standard Nutrition Protocol (SNP), provided an average protein regimen, administered by combined enteral and parenteral nutrition (PN) according to the European Society of Pediatric Gastroenterology and Nutrition (ESPGHAN) Guidelines $(17,18)$. This protocol entailed four different phases of enteral nutrition. In phase 1 (minimal enteral feeding [MEF]), minimal milk feeds $(10-15 \mathrm{ml} / \mathrm{kg} /$ day $)$ were administered to stimulate the anatomical and functional maturation of the gut and to reduce NEC risk (19). During this period, recommended nutrient intakes were guaranteed by $\mathrm{PN}$, started within the first $24 \mathrm{~h}$ of life. PN was prescribed according to the ESPGHAN recommendations (17): starting composition consisted of 6 $\mathrm{mg} / \mathrm{kg} /$ day of glucose and $2-2.5 \mathrm{~g} / \mathrm{kg} /$ day of aminoacids, which were incremented to $3.5 \mathrm{~g} / \mathrm{kg} /$ day by day 6 . Lipids were introduced from day 3 and gradually increased to $0.5 \mathrm{~g} / \mathrm{kg} /$ day over the first week of life until the achievement of $3 \mathrm{~g} / \mathrm{kg} /$ day. Sodium and other electrolytes were added from day 3 onwards and adjusted in relation to serum values and diuresis.

Once feeding tolerance to MEF was obtained, feeds were increased by $15-20 \mathrm{ml} / \mathrm{kg} /$ day divided in 8 meals (phase 2) until the achievement of full feeding, defined as enteral volumes of $160 \mathrm{ml} / \mathrm{kg} /$ day (phase 3). Human milk fortification was started at volumes of $100 \mathrm{ml} / \mathrm{kg} /$ day using Aptamil BMF 4.4\% (1,6-1,98 gr proteins $/ 100 \mathrm{ml}$ of milk) at meal administration. If clinical deterioration or symptoms of feeding intolerance (i.e., abdominal distention, absent bowel sounds, persistently bilious or bloody gastric residuals and/or bloody stools) (20), suspected sepsis, NEC or other surgical problems occurred at any phase, enteral feeds were withheld. According to inclusion criteria, 26 ELBW infants were recruited in SNP group.

The nutritional protocol of Bufalini Hospital's NICU was named Aggressive Nutrition Protocol (ANP). According to this protocol, preterm neonates were fed with fresh OMM or DM since their first day of life. Feeds were started at volumes of $10-15 \mathrm{ml} / \mathrm{kg} /$ day, divided in 10 meals; when an adequate feeding tolerance was established, feeds were increased by 20 $25 \mathrm{ml} / \mathrm{kg} /$ die. Protein fortification of HM was started from day 3 (when volume were about $40 \mathrm{ml} / \mathrm{kg}$ ) onwards at protein intakes of $0.5 \mathrm{~g} / 100 \mathrm{ml}$ of milk with Pro-expert PS (Aptamil) or Protifar (Nutricia), and was incremented to $1 \%$ over the next $24 \mathrm{~h}$. When infants tolerated feed volumes of $100 \mathrm{ml} / \mathrm{kg} /$ day, BMF (Aptamil) at a concentration of $3 \mathrm{~g} / 100 \mathrm{ml}$ was added to Pro-expert PS, and 
increased to $5 \mathrm{~g} / 100 \mathrm{ml}$ over the next days. The amount of protein fortification was adjusted according to the newborn's blood urea and acid-base status, monitored twice a week (21): if blood urea was less than $40 \mathrm{mg} / \mathrm{dl}$, protein fortification (Pro-expert PS) was yielded by $1.5 \%$, whereas BMF kept fixed at $5 \%$; no changes were made for levels between 40 and $50 \mathrm{mg} / \mathrm{dl}$ and normal acidbase status ( $\mathrm{pH}>7.30$ and $\mathrm{BE}<-4$ ). The maximum level of fortification was obtained with BMF at $5 \%$ plus Protifar or Proexpert PS at $1.5 \%$, depending on the infants' feeding tolerance, blood urea values and acid-base status. According to inclusion criteria, 26 ELBW infants were recruited in ANP group.

\section{Outcome Evaluation}

During hospitalization, growth parameters (weight, length and $\mathrm{HC}$ ), acid-base status, renal function, diuresis, enteral intakes, feeding tolerance, clinical history and the occurrence of clinical complications were regularly assessed and recorded in a clinical report form.

After discharge, as per national recommendations (22), all the enrolled infants were included in the clinical, neurological and neurodevelopmental follow-up of prematurity, which entails a term MRI scan at 40 weeks post-conceptional age and regular evaluations of the infant's growth and neurodevelopmental status up to 24 months CA. At each evaluation, weight, length and HC were measured to assess the infant's growth.

The psychomotor outcome of the enrolled infants was evaluated by two psychologists, with long-standing experience in developmental assessment, blind to the infant's nutrition group, using the Revised Griffiths Mental Development Scales (GMDSR) $0-2$ years (23), which are widely adopted for the evaluation of mental and psychomotor development in the context of the neurodevelopmental follow-up of preterm infants (24-28). These scales investigate five main areas (Locomotor-LOC, PersonalSocial - PS, Hearing and Language - HL, Eye-Hand Coordination - EH, Performance-PERF), providing a general quotient (GQ) of the infant's abilities adjusted for corrected age and 5 subquotients (SQ) for each functional area.

Data from the 12 and 24-month assessments were included in the present study.

\section{Statistical Analysis}

Statistical analysis was performed using Statistical Package for Social Science software for Microsoft Windows (SPSS) version 21.0. Data distribution was checked using KolmogorovSmirnov test; all data showed a normal distribution. Clinical characteristics of the study groups were compared by Pearson's chi-squared test and MANOVA.

Possible differences between the study groups in terms of length of NICU stay, growth parameters and in-hospital outcomes were evaluated by MANOVA test. Furthermore, the effects of study group (SNP and ANP), child's age (12 and 24 months CA), and their interaction on anthropometric data and psychomotor scores at post-discharge assessments were tested through Repeated Measure MANOVA. Maternal education and the infant gestational age were included as variables in order to control their possible influence, as emerged in previous literature $(9,24)$.
Finally, the association among intra-hospital variables and anthropometric data and psychomotor scores at postdischarge assessments was investigated with Pearson correlation coefficients. Fisher test $(F)$ and eta squared $\left(\eta^{2}\right.$ p) values were reported.

Significance level was set at $p \leq 0.05$.

\section{RESULTS}

A total of 52 neonates were included in the present study, 26 in the SNP group and 26 in the ANP group. The infants' characteristics are detailed in Table 1; while the two study groups were similar in terms of GA and anthropometric characteristics at birth, a significant difference in the distribution of gender, twinhood and mechanical ventilation [MV] was observed. Subsequent analyses showed that infant gender and twinhood did not significantly influence anthropometric data and GMDS scores. For this reason, these variables were not included in further analyses. On the contrary, MV showed a significant association with the outcome scores and was, therefore, controlled in subsequent analyses.

Globally, $60 \%$ of the enrolled infants received OMM and $40 \%$ pasteurized DM from the local hospital bank.

Eventually, groups were homogeneous for the following maternal characteristics: education, nationality and age (Table 1).

Parenteral and enteral protein intakes for the two groups over the first 4 weeks of life are detailed in Table 2. For each week the daily protein intake was significantly higher in the ANP group compared to SNP group. The high-protein nutritional regimen was well tolerated by the ANP group; no difference in the rate of metabolic acidosis and in serum creatinine levels during NICU stay was seen compared to the SNP group.

The rate of infants fed exclusively with OMM at discharge was $62.5 \%$ in the ANP group and $65.6 \%$ in the SNP group.

\section{In-hospital Outcomes}

In-hospital outcomes are detailed in Table 3. Infants in the ANP group showed significantly higher growth rates for weight and $\mathrm{HC}\left[F_{(1,47)}=5.95 ; P=0.021 ; F_{(1,47)}=7.60 ; P=0.010\right.$, respectively], but not for length, when compared to SNP. PN duration and the length of NICU stay were significantly shorter in the ANP group compared to the SNP $\left[F_{(1,47)}=15.87\right.$; $P<0.0005 ; F_{(1,47)}=21.85 ; P<0.0005$, respectively] (Table 3).

\section{Post-discharge Outcomes}

No pathological findings at term MRI were observed in the infants enrolled. At 24 months CA, no child developed cerebral palsy.

Anthropometric measures at 12 and 24 months CA in the two groups are provided in Table 4. Repeated measure MANOVA showed no significant effect of the Study Group on weight and length between two groups, whereas head circumference was significant higher in the ANP than in SNP group $[\mathrm{SNP}$ mean $=45.64 \pm 0.29$; $\mathrm{ANP}$ mean $=46.80 \pm$ $\left.0.31 ; F_{(1,40)}=7.844 ; P=0.008\right]$. A significant interaction between Study Group and Child's Age emerged for the children length $\left[F_{(1,40)}=27.170 ; P<0.0005\right]$ : at 24 months CA SNP 
TABLE 1 | Biological, socio-demographic and medical characteristics of the two groups.

\begin{tabular}{|c|c|c|c|c|}
\hline & SNP & ANP & $F / X^{2}$ & $P$ \\
\hline Birth-weight (g), mean (SD), range & 773 (165), 445-1000 & 826 (136), 692-986 & 0.11 & 0.74 \\
\hline Head circumference (cm), mean (SD), range & 25.3 (2.55), 2 2-31 & 24.9 (1.59), 22.8-29 & 0.59 & 0.44 \\
\hline Gestational age (weeks), mean (SD), range & 27.5 (1.68), 23-31 & 28.0 (1.75), 2 4-31 & 0.30 & 0.59 \\
\hline Twinhood, $n(\%)$ & $8(30.8)$ & $2(7.7)$ & 4.46 & 0.03 \\
\hline $\mathrm{MV}, n(\%)$ & $13(50.0)$ & $3(11.5)$ & 9.03 & 0.003 \\
\hline SGA, $n(\%)$ & $11(42.3)$ & $12(46.2)$ & 0.08 & 0.78 \\
\hline BPD, $n(\%)$ & $9(34.6)$ & $5(19.2)$ & 1.56 & 0.21 \\
\hline PDA, $n(\%)$ & $11(42.3)$ & $7(26.9)$ & 1.36 & 0.24 \\
\hline Maternal age, mean (SD), range & 32.54 (4.37), 24-42 & 34.55 (4.25), 23-41 & 2.35 & 0.13 \\
\hline
\end{tabular}

SNP, Standard Nutrition Protocol; ANP, Aggressive Nutrition Protocol; MV, mechanical ventilation, SGA, small for gestational age, BPD, bronchopulmonary dysplasia.

TABLE 2 | Mean values (standard deviation) of parenteral, enteral and total protein intakes in the two groups during the first 4 weeks of life.

\begin{tabular}{|c|c|c|c|c|c|}
\hline & & SNP & ANP & $\boldsymbol{F}$ & $P$ \\
\hline & Parenteral & 1.39 (0.34) & $1.20(0.48)$ & & $<0.0005$ \\
\hline & Total & $1.46(0.36)$ & $1.99(0.50)$ & 12.77 & 0.001 \\
\hline \multirow[t]{2}{*}{ Week 2} & Enteral & $0.39(0.37)$ & $3.08(1.27)$ & 48.31 & $<0.0005$ \\
\hline & Total & $1.69(0.29)$ & 3.65 (0.99) & 41.47 & $<0.0005$ \\
\hline \multirow[t]{3}{*}{ Week 3} & Enteral & $1.03(0.77)$ & $4.22(0.87)$ & 51.46 & $<0.0005$ \\
\hline & Parenteral & $0.63(0.52)$ & $0.00(0.00)$ & & $<0.0005$ \\
\hline & Total & $1.72(0.52)$ & $4.22(0.87)$ & 73.68 & $<0.0005$ \\
\hline Week 4 & Enteral & $1.72(0.99)$ & $4.36(0.84)$ & 32.66 & $<0.0005$ \\
\hline
\end{tabular}

Values describe g/kg/day. SNP, Standard Nutrition Protocol; ANP, Aggressive Nutrition Protocol.

children were taller than ANP ones $(P=0.04)$, whereas no significant difference for weight and head circumference was observed.

Psychomotor data at 12 and 24 months CA in the two groups are provided in Table 5. Mean values of GQ and SQ scores fell within normal ranges ${ }^{22}$ in both groups at 12 and 24 months except for PERF mean values in the SNP group at 24 months, which fell below the lower normal threshold. Despite no significant differences between SNP and ANP emerged, the interaction between Study Group and Child's Age significantly influenced the GQ $\left[F_{(1,40)}=9.062 ; P=0.005\right]$ and the following SQ: PS $\left[F_{(1,40)}=10.743, P=0.002\right]$, and PERF $\left[F_{(1,40)}=6.653\right.$, $P=0.014]$ (Figure 1). Bonferroni post hoc analyses showed that
QG, PS and PERF mean scores significantly decreased from 12 to 24 months CA [ $P=0.003 ; P=0.018 ; P=0.006$, respectively] but only in SNP group; moreover, PS quotients of ANP children (but non SNP ones) significantly increased from 12 to 24 months CA $[P=0.047]$ (Figure 1). Eventually, when compared to SNP, ANP children showed higher PERF scores at 24 months CA $[P=0.013]$ (Figure 1).

No significant effect of Child's Age emerged on anthropometric nor psychomotor outcomes.

Protein intakes in the first 2 weeks of life positively correlated with $\mathrm{HC}$ at 24 months $\mathrm{CA}(P=0.031)$. No significant correlation between protein intakes in the first 2 weeks and GMDS quotients were observed. 
TABLE 3 | In-Hospital Outcomes.

\begin{tabular}{|c|c|c|c|c|}
\hline & SNP & ANP & $\mathrm{F} / \mathrm{X} 2$ & $P$ \\
\hline & $(n=26)$ & $(n=26)$ & & \\
\hline Weight gain (gr/kg/day), mean (SD), range & $15.20(2.8), 9.7-23.9$ & 18.87 (3.0), 13.2-25.0 & 5.95 & 0.021 \\
\hline Length growth (cm/week), mean (SD), range & $0.95(0.5), 0.1-2.3$ & $0.88(0.2), 0.3-1.4$ & 0.62 & NS \\
\hline Head circumference growth (cm/week), mean (SD), range & $0.52(0.2), 0.2-0.9$ & $0.70(0.2), 0.1-1.1$ & 7.60 & 0.010 \\
\hline Milk volume, $\mathrm{ml} / \mathrm{kg}$, mean (SD), range & 150.52 (17.6), 115.6-200.9 & 160.7 (7.3), 149.3-198.8 & 0.12 & NS \\
\hline Days of $P N$, mean $(S D)$, range & 38.75 (29.6), 9-106 & $7.36(2.7), 2-14$ & 15.86 & $<0.0005$ \\
\hline Days to achieve full feeding, mean(SD), range & 28.50 (17.2), 9-78 & $7.50(2.0), 4-12$ & 28.40 & $<0.0005$ \\
\hline Weight at full feeding, mean(SD), range & 895.42 (294.8), 535-1620 & 748.8 (112.70),526-940 & 2.68 & NS \\
\hline Days of hospitalization, mean (SD), range & $78.08(21.32), 46-145$ & $60.0(13.3), 31-81$ & 21.85 & $<0.0005$ \\
\hline EUGR, n (\%) & $22(84.6 \%)$ & $16(61.5 \%)$ & 3.52 & 0.06 \\
\hline
\end{tabular}

SNP, Standard Nutrition Protocol; ANP, Aggressive Nutrition Protocol; PN, Parenteral Nutrition; EUGR, Extra-Uterine Growth Restriction.

TABLE 4 | Anthropometric data.

\begin{tabular}{|c|c|c|c|c|c|c|c|}
\hline & \multicolumn{2}{|c|}{$\begin{array}{c}\text { SNP } \\
(n=26)\end{array}$} & \multicolumn{2}{|c|}{$\begin{array}{c}\text { ANP } \\
(n=26)\end{array}$} & \multicolumn{3}{|c|}{ RM-MANOVA } \\
\hline & Mean(SD) & Range & Mean(SD) & Range & $F$ & $P$ & $\eta p^{2}$ \\
\hline Weight (g) & & & & & 2.509 & 0.121 & 0.059 \\
\hline 12 mo. ca & 8027.7 (1109) & 5915-10660 & 8546.15 (1175.8) & 6800-10900 & & & \\
\hline 24 mo. ca & $10375.8(1363)$ & 8110-13700 & $10572.31(1280.7)$ & $8530-13200$ & & & \\
\hline 24 mo. ca & $84.7(3.20)$ & $80-92$ & $82.2(3.15)$ & $76-89$ & & & \\
\hline $\mathrm{HC}(\mathrm{cm})$ & & & & & 2.985 & 0.092 & 0.069 \\
\hline 12 mo. ca & $44.9(1.46)$ & $41-47$ & $45.8(1.57)$ & $43-48$ & & & \\
\hline 24 mo.ca & $47.15(1.25)$ & $44.3-49.4$ & $47.8(1.24)$ & $45.5-50$ & & & \\
\hline
\end{tabular}

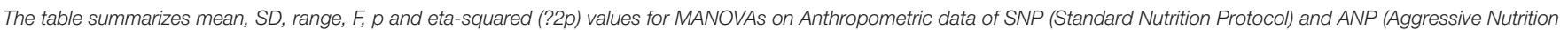
Protocol) infants at 12 and 24 months (corrected age).

\section{DISCUSSION}

According to our results, higher protein intakes over the first 4 weeks of life in ELBW infants are associated with improved growth of $\mathrm{HC}$ and psychomotor outcomes at 24 months CA, thus highlighting the importance of in-hospital nutrition. Moreover, the present data confirm that adjustable fortification of HM combining different commercially available concentrated HM fortifiers effectively allows the achievement of protein intakes and protein/energy ratio currently recommended for the ELBW population during the first weeks of life.

While more is known about recommended protein intakes for very-low-birth-weight infants, little data are currently available for ELBW babies. Basing on empirical calculations, an enteral protein intake of $4.0-4.5 \mathrm{~g} / \mathrm{kg} / \mathrm{day}$ is currently recommended for infants up to $1000 \mathrm{~g}$ of weight to prevent protein deficit accumulation and to aim at growth patterns similar to intrauterine ones (18). Particular attention should be paid also at protein/energy ratio that, for infants $<1000 \mathrm{~g}$, ranges from 3.2 to $4.1 \mathrm{~g} / 100 \mathrm{kcal}$. In growth-restricted infants, energy intakes can be increased; however, if not accompanied by adequate protein intakes, growth is achieved at the expenses of body composition, ensuing in a high percentage of body fat (19) that could contribute to worsen the increased intraabdominal adiposity observed in ELBW neonates and to heighten their risk of metabolic complications in later life (29).

Assuming HM protein contents between 0.8 and $1.2 \mathrm{~g} / 100 \mathrm{ml}$ $(10,11)$, the estimated protein intakes at maximum fortification levels and at enteral intakes of $160 \mathrm{ml} / \mathrm{kg} /$ day were $3.5 \mathrm{~g} / \mathrm{kg} /$ day in the SNP group and $4.8 \mathrm{~g} / \mathrm{kg} /$ day in the ANP group, whereas the protein/energy ratio (protein $\mathrm{g} / 100 \mathrm{Kcal}$ ) ranged between $1.9-2.3$ and 3.0-3.3, respectively. Hence, according to the above recommendations, the estimated protein requirements were met in the ANP but not in the SNP group; consistently, the latter showed higher EUGR rates.

In 2013, Cormack et al. (30) investigated the effects of protein intake equal or greater to $4 \mathrm{~g} / \mathrm{kg} /$ day provided during the first week of life in a predominantly HM fed cohort of ELBW babies, reporting a significant association between protein intake and inhospital growth: the higher the intake, the smaller the $\mathrm{z}$-score change between birth and discharge. 
TABLE 5 | Infant's psychomotor mean scores at post-discharge assessments.

\begin{tabular}{|c|c|c|c|c|c|c|c|}
\hline & \multicolumn{2}{|c|}{$\begin{array}{c}\text { SNP } \\
(n=26)\end{array}$} & \multicolumn{2}{|c|}{ ANP $(n=26)$} & \multicolumn{3}{|c|}{ RM-MANOVA } \\
\hline & Mean(SD) & Range & Mean(SD) & Range & $\boldsymbol{F}$ & $P$ & $\eta p^{2}$ \\
\hline GQ score, mean (SD), range & & & & & 9.062 & 0.005 & 0.197 \\
\hline 12 mo. ca & $103.24(10.66)$ & $72-119$ & $97.03(11.79)$ & $66-117$ & & & \\
\hline 24 mo. ca & $97.03(11.77)$ & $68-113$ & $101.03(110.76)$ & $81-120$ & & & \\
\hline $24 \mathrm{mo} . \mathrm{ca}$ & 98.94 (19.30) & $60-135$ & $113.93(20.59)$ & $60-135$ & & & \\
\hline PS score, mean (SD), range & & & & & 10.743 & 0.002 & 0.225 \\
\hline $12 \mathrm{mo} . \mathrm{ca}$ & $107.28(13.60)$ & $64-122$ & $92.36(13.20)$ & $56-114$ & & & \\
\hline 24 mo.ca & $99.60(13.45)$ & $59-119$ & $99.58(12.87)$ & $66-119$ & & & \\
\hline HL score, mean (SD), range & & & & & 0.279 & 0.601 & 0.007 \\
\hline 12 mo. ca & $102.08(14.55)$ & $79-128$ & $97.22(15.93)$ & $68-122$ & & & \\
\hline 24 mo.ca & $98.89(14.28)$ & $71-123$ & $103.62(14.27)$ & $76-123$ & & & \\
\hline PERF score, mean (SD), range & & & & & 6.653 & 0.014 & 0.152 \\
\hline 12 mo. ca & $102.32(12.09)$ & $76-122$ & $102.32(13.12)$ & $63-123$ & & & \\
\hline $24 \mathrm{mo} . \mathrm{ca}$ & 90.99 (18.74) & $50-117$ & $105.53(12.37)$ & $77-121$ & & & \\
\hline
\end{tabular}

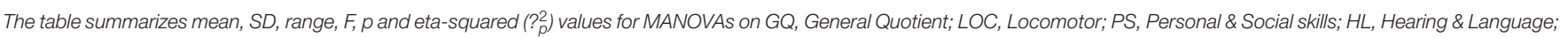

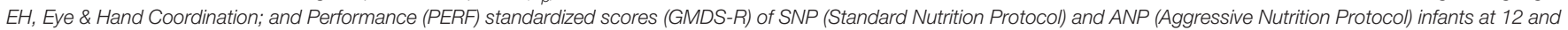
24 months (corrected age).

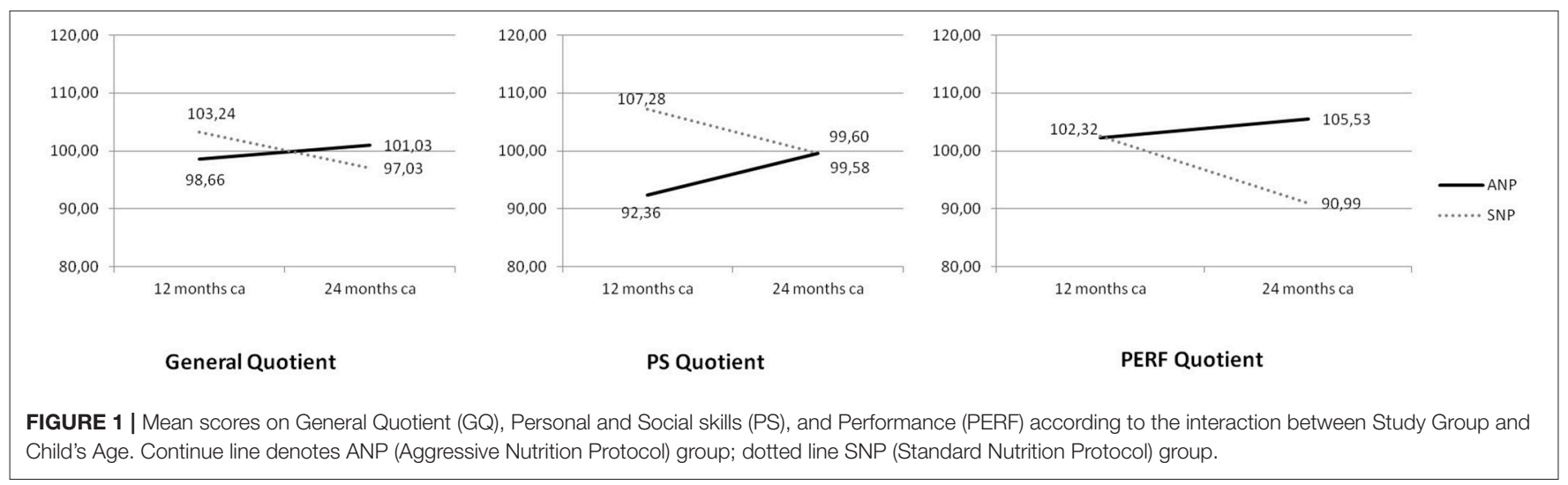

In addition to the beneficial effects on in-hospital outcomes and head circumference growth at 12 and 24 months CA, the present study has demonstrated increased length after discharge. However, an unattended result regards the outcome of length, where ANP infants obtained worse scores than those of SNP group. According to previous researches $(27,28)$, length was measured to the nearest $\mathrm{cm}$ using a length board: it could be possible this kind of measure is not adequately sensitive and has a increased risk of measurement bias. Further studies are needed to better explain this result.

Our results are in line with Stephen et al. (12), who had previously described a positive correlation between increased first-week protein and energy intakes and higher Mental Development Index scores at 18 months CA in an ELBW population. Despite ANP and SNP did not differ in the GMDS quotients mean scores, the trajectory of these scores is significantly different in the scales, with a lower decrement and a better psychomotor development at 24 months CA in ELBW infants receiving early and high protein intakes. Specifically, ANP children not only show better personal-social skills outcome at 24 months, but their GQ, PS and PERF mean quotients do not decrease as emerged in SNP group. Despite preliminary, this result is promising: future studies could deepen if this intervention reduce the negative effect of severely preterm birth on long term development. The Hearing and Language quotients is the only where effects did not emerged, confirming as this area is particularly weak for very preterm infants $(24,26,31)$. 
Taken together, these results suggest a long-lasting beneficial influence of this protein regimen on cerebral maturation.

Recently, a Cochrane review investigating the effect of high protein intake in formula-fed low-birth-weight infants has reported elevated blood urea nitrogen levels and an increased incidence of metabolic acidosis in association with protein intakes ranging between 3 and $4 \mathrm{~g} / \mathrm{kg} /$ day (32). However, little is known about the incidence of these adverse effects in HM-fed ELBW infants. In the present study, the ANP group did not show increased blood urea or higher rates of metabolic acidosis, suggesting that this high-protein regimen was adequately tolerated by the study ELBW population.

Although a trend toward an earlier introduction of enteral feeds has occurred over the last few years, ELBW infants often do not begin enteral nutrition for several days and do not reach full feeding for weeks. In the ANP population, enteral feeds were introduced since the first day of life and faster rates of feeding advancement were adopted, resulting in earlier full feeding achievement, shortened PN duration -related complications and a significantly briefer length of hospitalization. The combination of these factors may have contributed to the improved psychomotor outcomes of ANP infants at 24 months CA; however, the design of the present study did not allow to define the role of each factor in determining the observed outcome.

A number of limits could be acknowledged for the present study. Firstly, the results need to be confirmed on wider samples. Secondly, a significant difference in the distribution of a clinical complication (mechanical ventilation) emerged. Despite this

\section{REFERENCES}

1. De Curtis M, Rigo J. The nutrition of preterm infants. Early Hum Dev. (2012) 88:S5-7. doi: 10.1016/j.earlhumdev.2011.12.020

2. Ehrenkranz RA, Dusick AM, Vohr BR, Wright LL, Wrage LA, Poole WK. Growth in the neonatal intensive care unit influences neurodevelopmental and growth outcomes of extremely low birth weight infants. Pediatrics (2006) 117:1253-61. doi: 10.1542/peds.2005-1368

3. Tan MJ, Cooke RW. Improving head growth in very preterm infants - a randomised controlled trial I: neonatal outcomes. Arch Dis Child. (2008) 93:F337-41. doi: 10.1136/adc.2007.124230

4. Clark RH, Thomas P, Peabody J. Extrauterine growth restriction remains a serious problem in prematurely born neonates. Pediatrics (2003) 111: 986-90. doi: 10.1542 /peds.111.5.986

5. Terrin G, De Curtis M. Nutrizione enterale e parenterale nel neonato prematuro. Prospettive Pediatr. (2015): 45:41-52.

6. Henriksen C, Westerberg AC, Rønnestad A, Nakstad B, Veierød MB, Drevon $\mathrm{CA}$, et al. Growth and nutrient intake among very-low-birth-weight infants fed fortified human milk during hospitalisation. Br J Nutr. (2009) 102:117986. doi: 10.1017/S0007114509371755

7. Schneider J, Fischer Fumeaux CJ, Duerden EG, Guo T, Foong J, Graz MB, et al. Nutrient intake in the first two weeks of life and brain growth in preterm neonates. Pediatrics (2018) 1414:3. doi: 10.1542/peds.2017-2169

8. Rozé JC, Darmaun D, Boquien CY, Flamant C, Picaud JC, Savagner C, et al. The apparent breastfeeding paradox in very preterm infants: relationship between breast feeding, early weight gain and neurodevelopment based on results from two cohorts, EPIPAGE and LIFT. BMJ Open (2012) 2:e000834. doi: 10.1136/bmjopen-2012-000834

9. Gibertoni D, Corvaglia L, Vandini S, Rucci P, Savini S, Alessandroni R, et al. Positive effect of human milk feeding during nicu hospitalization on 24 month variables was controlled in analyses, results need replication. Thirdly, the small sample size did not allow to focus on SGA infants, which are known as a high risk population (32). Further studies are therefore recommended which should consider also these factors.

In conclusion, a high-protein regimen, associated with an early introduction and advancement of exclusive HM feeds, can lead to improved in-hospital growth, lower rates of EUGR, shorter length of NICU stay and better psychomotor and growth outcomes at 24 months CA in ELBW preterm infants. Further larger studies are needed to confirm these preliminary data, to assess the contribution of different nutrient components and other clinical or environmental variables on post-discharge growth and neurodevelopment and to investigate possible long-term effects of high-protein regimens in this high-risk population.

\section{AUTHOR CONTRIBUTIONS}

EM and $A B$ prepared the study design, organized the sample recruitment, collected data, and contributed to the writing of the manuscript's introduction, discussion, and references sections. LM, SM, AA, and SS contributed to the recruitment of the sample and to data collection. LC, GF, AS, FA, and MS contributed to prepare the study design and supervised data collection and the research team. EN performed statistical analysis, prepared the tables, and contributed to write all sections of the manuscript. All authors reviewed and approved manuscript for publication. neurodevelopment of very low birth weight infants: an italian cohort study. PLoS ONE (2015) 10:e0116552. doi: 10.1371/journal.pone.0116552

10. Arslanoglu S, Moro GE, Ziegler EE. Preterm infants fed fortified human milk receive less protein than they need. J Perinatol. (2009) 29:489-92. doi: 10.1038/jp.2009.50

11. Corvaglia L, Aceti A, Paoletti V, Mariani E, Patrono D, Ancora G, et al. Standard fortification of preterm human milk fails to meet recommended protein intake: bedside evaluation by Near-Infrared-Reflectance-Analysis. Early Hum Dev. (2010) 86:237-40. doi: 10.1016/j.earlhumdev.2010. 04.001

12. Stephens BE, Walden RV, Gargus RA, Tucker R, McKinley L, Mance M, et al. First-week protein and energy intakes are associated with 18-month developmental outcomes in extremely low birth weight infants. Pediatrics (2009) 123:1337-43. doi: 10.1542/peds.2008-0211

13. McCrea HJ, Ment LR. The diagnosis, management, and postnatal prevention of intraventricular hemorrhage in the preterm neonate. Clin Perinatol. (2008) 35:777-92. doi: 10.1016/j.clp.2008.07.014

14. Khwaja O, Volpe JJ. Pathogenesis of cerebral white matter injury of prematurity. Arch Dis Child - Fetal Neonatal Ed. (2007) 93: F153-61. doi: 10.1136/adc.2006.108837

15. Hellström A, Smith LEH, Dammann O. Retinopathy of prematurity. Lancet (2013) 382:1445-57. doi: 10.1016/S0140-6736(13)60178-6

16. Neu J, Walker WA. Necrotizing enterocolitis. N Engl J Med. (2011) 364:25564. doi: 10.1056/NEJMra1005408

17. Koletzko B, Goulet O, Hunt J, Krohn K, Shamir R. 1. Guidelines on paediatric parenteral nutrition of the european society of paediatric gastroenterology, hepatology and nutrition (ESPGHAN) and the European Society for Clinical Nutrition and Metabolism (ESPEN), Supported by the European Society of Paediatric Research (ESPR). J Pediatr Gastroenterol Nutr. (2005) 41:S1-87. doi: 10.1097/01.mpg.0000181841.07090.f4 
18. Agostoni C, Buonocore G, Carnielli VP, De Curtis M, Darmaun D, Decsi $\mathrm{T}$, et al. Enteral nutrient supply for preterm infants: commentary from the European Society of Paediatric Gastroenterology, Hepatology and Nutrition Committee on Nutrition. J Pediatr Gastroenterol Nutr. (2010) 50:85-91. doi: 10.1097/MPG.0b013e3181adaee0

19. Ramani M, Ambalavanan N. Feeding practices and necrotizing enterocolitis. Clin Perinatol. (2013) 40:1-10. doi: 10.1016/j.clp.2012.12.001

20. Schanler RJ. The low-birth-weight infant. In: WA Walker, JB Watkins editors. Nutrition in Pediatrics: Basic Science and Clinical Applications. 2nd editon. Hamilton, Ontario: BC Decker Inc., (1996). p. 392-412.

21. Arslanoglu S, Bertino E, Coscia A Tonetto P, Giuliani F, Moro GE. Update of adjustable fortification regimen for preterm infants: a new protocol. J Biol Regul Homeost Agents (2012) 26: 65-67.

22. Romagnoli C. Percorsi Assistenziali Neonatologici. Milano:Biomedia (2013).

23. Griffiths R. The Griffiths Mental Development Scales From Birth to Two Years. Oxford: The 1996 revision Hogrefe (1996).

24. Sansavini A, Savini S, Guarini A, Broccoli S, Alessandroni R, Faldella G. The effect of gestational age on developmental outcomes: a longitudinal study in the first two years of life. Child Care Health Dev. (2011) 37:26-36. doi: 10.1111/j.1365-2214.2010.01143.x

25. Giannì ML, Picciolini O, Vegni C, Gardon L, Fumagalli M, Mosca F. Twelvemonth neurofunctional assessment and cognitive performance at 36 months of age in extremely low birth weight infants. Pediatrics (2007) 120:1012-9. doi: 10.1542/peds.2006-3364

26. Neri E, Agostini F, Baldoni F, Facondini E, Biasini A, Monti F. et al. Preterm infant development, maternal distress and sensitivity: the influence of severity of birth weight. Early Hum Dev. (2017) 106-107:19-24. doi: 10.1016/j.earlhumdev.2017.01.011

27. Biasini A, Monti F, Laguardia MC, Stella M, Marvulli L, Neri E. High Protein Intake in human /maternal milk fortification for $</=1250$ gr infants: intrahospital growth and neurodevelopmental outcome at two years. Acta Biomed. (2017) 88:470-6. doi: 10.23750/abm.v88i4.5316
28. Biasini A, Neri E, China M, Monti F, Di Nicola P, Bertino E. Higher protein intake strategy in human milk fortification for preterm infants feeding. Auxological and Neurodevelopmental outcome. J Biol Regul Homeost Agents (2012) 26:43-7.

29. Uthaya S, Thomas EL, Hamilton G, Doré CJ, Bell J, Modi N. Altered adiposity after extremely preterm birth. Pediatr Res. (2005) 57:211-5. doi: 10.1203/01.PDR.0000148284.58934.1C

30. Cormack BE, Bloomfield FH. Increased protein intake decreases postnatal growth faltering in ELBW babies. Arch Dis Child Fetal Neonatal Ed. (2013) 98:F399-404. doi: 10.1136/archdischild-2012-302868

31. Vohr B. Speech and language outcomes of very preterm infants. Semin Fetal Neonatal Med. (2014) 19:78-83. doi: 10.1016/j.siny.2013. 10.007

32. Fenton TR, Premji SS, Al-Wassia H, Sauve RS. Higher versus lower protein intake in formula-fed low birth weight infants. Cochrane Database Syst Rev. (2014) CD003959. doi: 10.1002/14651858.CD0 03959

Conflict of Interest Statement: The authors declare that the research was conducted in the absence of any commercial or financial relationships that could be constructed as a potential conflict of interest.

The handling editor declared a shared affiliation, though no other collaboration, with one of the authors $\mathrm{AB}$.

Copyright (c) 2018 Mariani, Biasini, Marvulli, Martini, Aceti, Faldella, Corvaglia, Sansavini, Savini, Agostini, Stella and Neri. This is an open-access article distributed under the terms of the Creative Commons Attribution License (CC BY). The use, distribution or reproduction in other forums is permitted, provided the original author(s) and the copyright owner(s) are credited and that the original publication in this journal is cited, in accordance with accepted academic practice. No use, distribution or reproduction is permitted which does not comply with these terms. 